\title{
ATMOSPHERIC CHANGES OBSERVED IN ANTARCTICA RELATED TO THE SUN-EARTH INTERACTIONS
}

http://dx.doi.org/10.4322/apa.2014.055

\author{
Emília Correia ${ }^{1,2, *}$, Jean Pierre Raulin², Pierre Kaufmann², Hernan R. Gavilan
}

${ }^{1}$ Instituto Nacional de Pesquisas Espaciais, São José dos Campos, SP, Brazil

Escola de Engenharia,Centro de Rádio Astronomia e Astrofísica Mackenzie, Universidade Presbiteriana Mackenzie, Rua da Consolação, 930, Ed. Modesto Carvalhosa, $7^{\circ}$ andar, CEP 01302-907, São Paulo, SP, Brazil

\author{
*e-mail: ecorreia@craam.mackenzie.br
}

\begin{abstract}
Here we present the ionosphere behavior obtained from measurements done with the ionosonde operating at Comandante Ferraz Brazilian Antarctic Station (EACF) in 2011. We also discuss its long-term behavior obtained from 2004 to 2011 using very low frequency radio signals and GPS measurements. During quiet periods the ionosphere is controlled by the solar Lyman alpha radiation, presenting variations closely associated with the 11-year sunspot number. But it is strongly affected by the excess of $X$-ray emission produced during the solar flares. The long-term studies of ionosphere behavior have also shown it presents strong variations during local wintertime, which were found to be closely related to the waves of neutral atmospheric origin. The studies of ionosphere behavior have been improving our understanding of its response to natural phenomena, and about its coupling with the other atmospheric layers. The energy exchange among atmospheric layers might be an important factor in the climate conditions/changes, which affect the terrestrial and marine environment, especially in the polar region.
\end{abstract}

Keywords: atmosphere, sun-earth interaction, atmospheric radio sounding

\section{Introduction}

The ionosphere is formed/maintained by the solar Lyman-alpha $(121.5 \mathrm{~nm})$ ionizing radiation during quiet conditions (Nicolet \& Aikin, 1960). This solar radiation presents variability in close association with the 11-year solar cycle, which affects the ionization processes of the low ionosphere (Lastovicka, 2006). This effect has been obtained from long-term measurements of very low radio frequency (VLF) signals propagating over long distances inside the Earth-ionosphere waveguide during the $22^{\text {nd }}$ and $23^{\text {rd }}$ solar cycles (Thomson \& Clilverd, 2000; Correia et al., 2011 , respectively). Since the maximum of the $24^{\text {th }}$ solar cycle will be during 2013-2014, the influence of the solar radiation in our atmosphere will increase in the next two years due to changes in its chemistry and physics produced by ionization process enhancements.

The ionosphere is also strongly affected by upward propagating gravity and planetary waves originated in the neutral atmosphere particularly during the local wintertime (Lastovicka, 2006). The effects of planetary waves were detected in the VLF measurements done from 2004-2011 at Comandante Ferraz Brazilian Antarctic Station (EACF) (Correia et al., 2011, 2013). The atmospheric waves have an important role in the energy and momentum transport from the lower to upper atmosphere layers, affecting the thermal structure and general circulation in the middle and upper atmosphere (Takahashi et al., 1999; Bageston et al., 2011). The year-to-year variation in ozone holes are also affected by differences in atmospheric temperature and circulation (e.g. Newman et al., 2008).

Here we present the solar activity in 2011 and its influence in the ionosphere obtained from ionosonde measurements done at EACF. Recent scientific results related to ionospheric behavior from 2007 to 2011 obtained with VLF measurements done at EACF and at Itapetinga Radio Observatory (ROI, Atibaia/Brazil), and from 2004 to 2011 obtained with GPS system operating at EACF are also presented and discussed. 


\section{Materials and Methods}

The ionosphere behavior is obtained using different radio sounding techniques:

VLF measurements are done in the $1-50 \mathrm{kHz}$ frequency range with 20ms time resolution using Atmospheric Weather Electromagnetic systems for Observation, Modeling and Education receivers - AWESOME (Scherrer et al., 2008) operating at $\mathrm{EACF}\left(62.11^{\circ} \mathrm{S}\right.$ and $58.41^{\circ} \mathrm{W}$, since 2007$)$ and at $\mathrm{ROI}\left(23.21^{\circ} \mathrm{S}\right.$ and $46.51^{\circ} \mathrm{W}$, since 2006$)$. VLF technique is used to study the lower part of the ionosphere, the D-region that is between 60 and $85 \mathrm{~km}$ of height.

The Vertical Total Electron Content (VTEC) of ionosphere is obtained using dual-frequency GPS receivers. The phase shifts produced by the dispersive nature of the plasma are directly proportional to VTEC, which is the integral line of the electron concentration along the path between the satellite and receiver. The ionosphere has been monitored at EACF since 2004 using a Javad GPS receiver with a best time resolution of $1 \mathrm{~s}$. VTEC is estimated using the first step of the Implementation of La Plata Ionospheric Model (LPIM) applicative developed in the National La Plata University (Argentine) (Brunini et al., 2008).

The ionosphere at EACF has also been monitored since 2009 using a Canadian Digital Ionosonde (CADI, MacDougall, 1997) that consists of one transmitter at

ISES Solar Cycle Sunspot Number Progression Observed data through Apr 2012

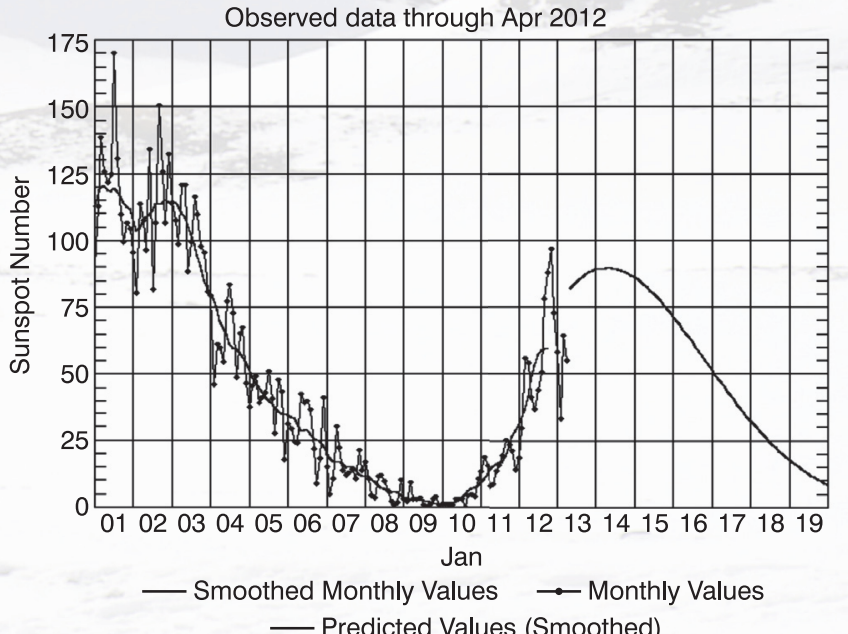

(a)

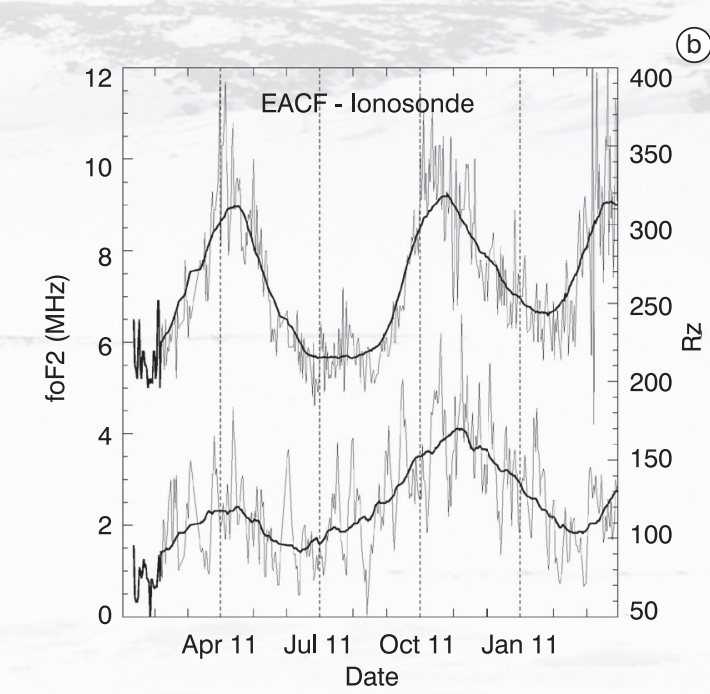

frequencies between 1 and $20 \mathrm{MHz}$, and four receivers to detect the reflected signals. The echoes of the reflected signal by the $\mathrm{F}$ and $\mathrm{E}$ regions of the ionosphere provide a profile of reflection frequency versus virtual height (ionogram), which gives information of the electron density (directly related to the reflection frequency) profile as a function of actual height (Piggott \& Rawer, 1972). The CADI is programmed to obtain ionograms each $5 \mathrm{~min}$ and drift measurements each $2.5 \mathrm{~min}$. The scaling of ionograms is obtained using the software developed at Universidade do Vale do Paraíba (UNIVAP) called the UNIVAP Digital Ionosonde Data Analysis (UDIDA) (Fagundes et al., 2005).

\section{Results}

\section{Solar activity in 2011}

We are in the ascending phase of the $24^{\text {th }}$ solar cycle, which started at the beginning of 2010 and which will reach its maximum during 2013-2014 as shown by the solar cycle sunspot progression presented in the Figure 1a (http:// www.swpc.noaa.gov/SolarCycle/, access: 22 May 2102). To evaluate the solar influence in the ionosphere on 2011 we compared the foF2 parameter, which gives information about the electron density at $\sim 200 \mathrm{~km}$ of height, with the daily sunspot number (Rz, http://sidc.oma.be/sunspotdata/, access: 21 May 2012) (Figure 1b). The foF2 here is

(a) 
the F2 layer critical frequency parameter estimated from ionograms at $\sim$ 16:00 UT (local noon time) obtained from CADI measurements done at EACF. The foF2 parameter shows that the ionosphere electron density changed in close association with the solar activity variation, presenting two peaks (April and November) that are present in the Rz data and a similar increase tendency during the year.
The effect of the increasing solar activity in the low ionosphere was also evaluated from the phase variations of VLF signals, particularly from correlation between the phase variations and the intensity of the X-ray flares. The intensity of the X-ray flares able to produce significant VLF phase variations increased from $\geq 3.0 \times 10^{-7} \mathrm{~W} / \mathrm{m}^{2}$ during the solar minimum (2007-2009), to $23.8 \times 10^{-7} \mathrm{~W} / \mathrm{m}^{2}$ and to $4.2 \times 10^{-7} \mathrm{~W} / \mathrm{m}^{2}$, respectively in 2010 and 2011 .
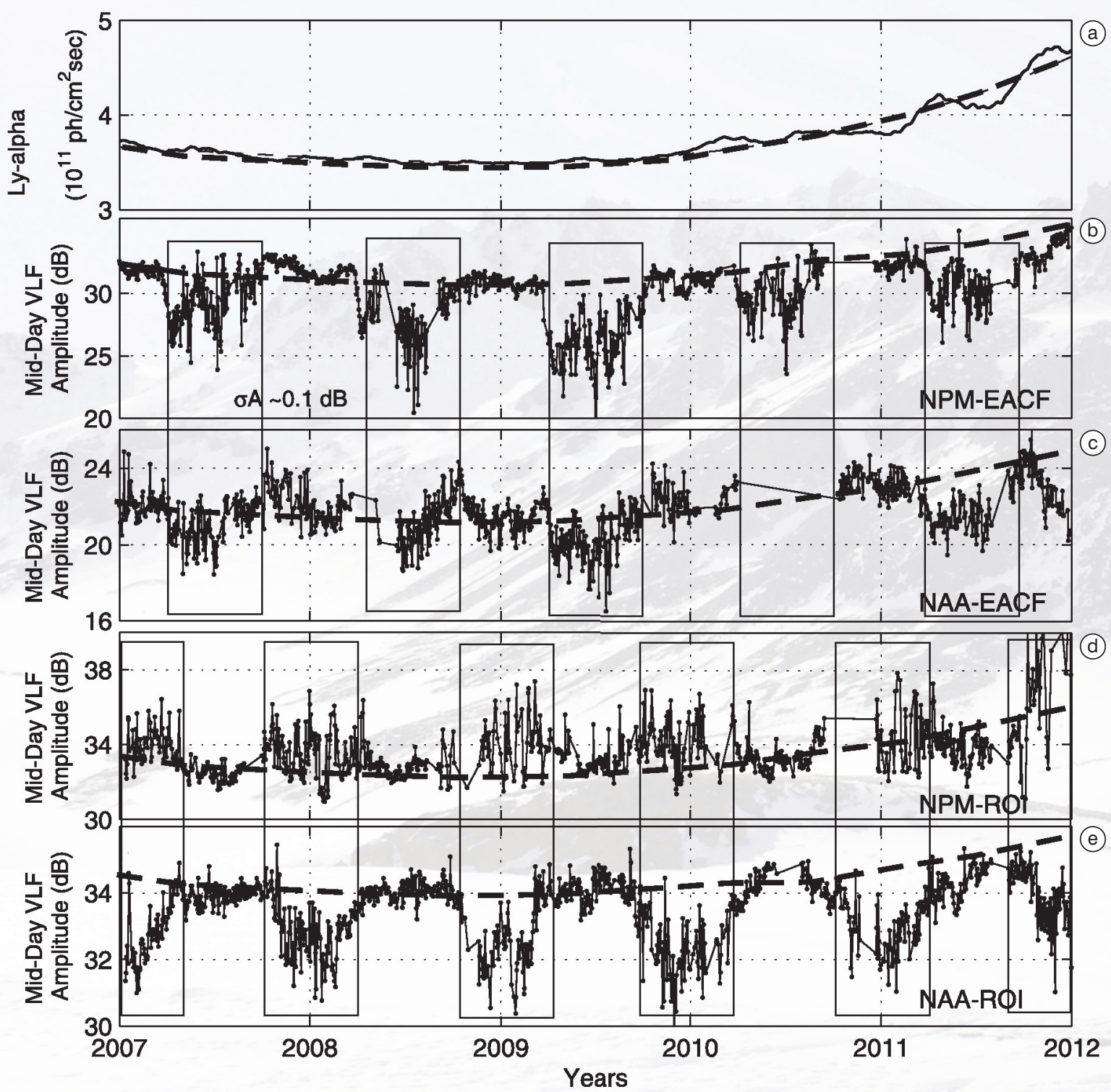

Figure 2. Comparison of the daily daytime VLF amplitude observed at paths NPM-EACF (b), NAA-EACF (c), NPM-ROI (d) and NAA-ROI (e) with the 27-day smoothed solar Lyman-alpha radiation (a) from 2007 to 2011. The vertical boxes identify the wintertime period in the southern (b and c panels) and northern hemisphere ( $d$ and e panels), when the influence of the planetary waves originated in the neutral atmosphere (adapted from Correia et al., 2013) is clear. 


\section{Ionosphere long-term behavior - \\ VLF measurements}

The study of the solar forcing in the ionosphere using the daytime VLF amplitude was done for the 2007-2011 period considering the VLF signals transmitted from NPM (Hawaii) and NAA (North Dakota) and received at EACF and ROI (Correia et al., 2013). The results, as expected, show the solar Lyman-alpha radiation (http://lasp.colorado. edu/lisird/lya/) control on the lower ionosphere, which was characterized by the VLF amplitude decline from 2007 to 2009 , when the $23^{\text {rd }}$ solar cycle reached its lowest activity level, followed by an increasing tendency with the starting of activity of the $24^{\text {th }}$ solar cycle (Figure 2). This result is in agreement with Correia et al. (2011), who obtained a good correlation during the decay phase of the $23^{\text {rd }}$ solar cycle (2004-2008). The daytime VLF amplitude also showed high day-to-day variations, which present a clear seasonal behavior occurring predominantly during local wintertime in all years. The VLF amplitude variations indicated a significant component in a 16-day period, typical of planetary waves of stratosphere/tropospheric origin.

\section{Ionosphere long-term behavior - GPS measurements}

The ionosphere behavior was evaluated from the study of monthly VTEC variations observed at EACF from 2004 to 2011 (Figure 3a). The analysis shows that VTEC presents a seasonal variation produced by the solar illumination, which slowly changes in close association with 11-year solar cycle as shown by the variation of the Ultraviolet radiation (30.4 nm, http://lasp.colorado.edu/lisird/lya/). This good correlation between VTEC and solar UV variation at local summer (January) and winter (July) seasons are clearly seen in Figure 3b.

\section{Discussion and Conclusion}

The Sun is the main energy source on Earth, being responsible for its environmental conditions and for life. On the other hand, the atmosphere is also an important element that filters part of the solar radiation that is harmful to terrestrial and marine life, especially in X-rays and ultraviolet spectral range. Solar radiation is not constant and presents variations in different time scales, mainly associated

(a)
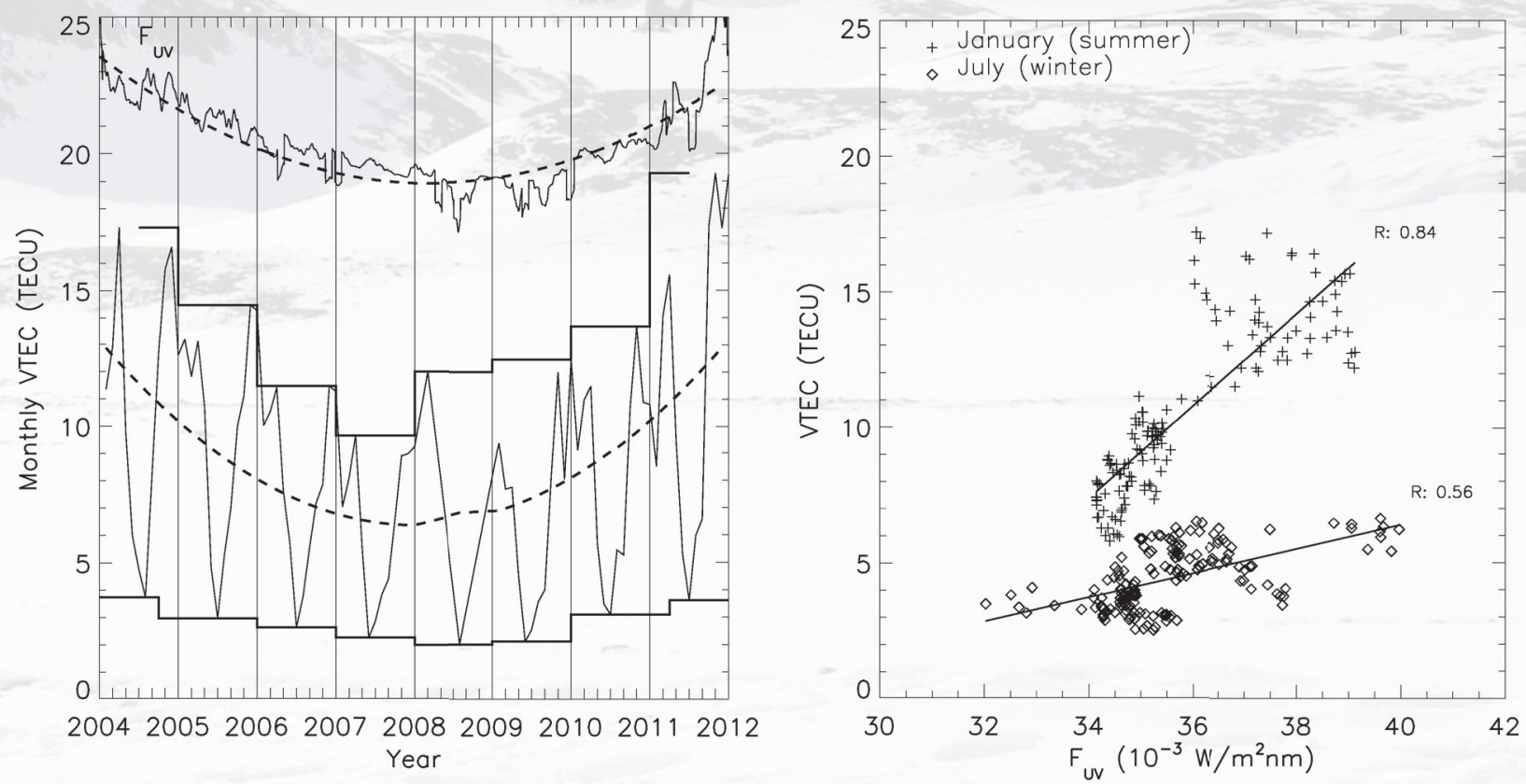

Figure 3. Daily maximum VTEC measured at EACF (lower curve) compared with 27-day smoothed solar UV radiation (upper curve) from 2004 to 2011 (a). Correlations between the daily maximum VTEC and the UV flux in January (summer) and in July (winter) (b). Figures adapted from Correia et al. (2012).

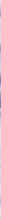


with the Gleissberg cycle ( $\sim 90$ years), Hale cycle ( $\sim 22$ years) and Schwabe cycle ( 11 years), as well as with 27 -days time scale associated with the solar rotation.

The more pronounced solar variations occur in an 11-year cycle, which is the main driver of the Earth's atmospheric conditions, as evidenced from long-term ionospheric studies and reinforced by the VLF amplitude increase observed during 2011 in close association with the enhancement of the $24^{\text {th }}$ solar cycle activity. Variations in shorter time scales (minutes to hours) occur in close association with the solar flares, whose excess of X-ray emission strongly affects the lower ionosphere. As the Sun becomes more active, the solar radiation increases and alters the atmosphere's chemistry and physics influencing the environmental conditions, and thus the terrestrial and marine life.

The studies have also shown that the upper atmosphere is also affected by atmospheric waves of troposphere/ stratosphere origin. These waves in their upward propagation strongly affect the ionosphere, especially during the local wintertime, evidencing a coupling between all atmospheric layers. Thus, the simultaneous monitoring of the atmospheric layers is important for understanding how the solar energy input is transported to lower atmosphere layers, and to define the role of solar radiation in the climate changes.

In the next two years this monitoring will be very important because the $24^{\text {th }}$ solar cycle will reach its maximum activity, and the solar energy input in our atmosphere will be at its highest level.

\section{Acknowledgements}

This work was partially sponsored by the Brazilian Antarctic Program/Ministry of the Environment (PROANTAR/ MMA, Portuguese acronym), National Council for Scientific and Technological Development (CNPq processes no.: 52.0186/06-0 and 556872/2009-6), the Interministerial Commission for Resources of the Sea (SECIRM, Portuguese acronym), the National Institute for Space Research (INPE, Portuguese acronym) and INCT-APA (Instituto Nacional de Ciência e Tecnologia Antártico de Pesquisas Ambientais, CNPq process $n^{\circ} 574018 / 2008-5$ and FAPERJ process $n^{\circ}$ E-16/170.023/2008). EC and the authors would like to thank the technicians Armando Hadano and José Roberto Chagas from INPE, for their support in Antarctica.

\section{References}

Bageston, J.V.; Wrasse, C.M.; Hibbins, R.E.; Batista, P.P.; Gobbi, D.; Tahakashi, H.; Fritts, D.C.; Andrioli, V.F.; Fechine, J. \& Denardini, C.M. (2011). Case study of a mesospheric wall event over Ferraz Station, Antarctica (62 ${ }^{\circ}$ S). Annales Geophysicae, 29(s/n): 209-19

Brunini, C.; Meza, A.; Gende, M. \& Azpilicueta, F. (2008). South American regional ionospheric maps computed by GESA: A pilot service in the framework of SIRGAS. Advances in Space Research, 42 (4): 737-44. http://dx.doi.org/10.1016/j. asr.2007.08.041

Correia, E.; Kaufmann, P.; Raulin, J-P.; Bertoni, F.C. \& Gavilán, H.R. (2011). Analysis of daytime ionosphere behavior between 2004 and 2008 in Antarctica. Journal of Atmospheric and Solar-Terrestrial Physics, 73: 2272-8.

Correia, E.; Paz, A.J. \& Gende, M.A. (2012). Characterization of GPS-TEC in Antarctica from 2004 to 2011. Annals of Geophysics. Submitted.

Correia, E.; Raulin, J-P.; Kaufmann, P.; Bertoni, F. \& Quevedo, M.T. (2013). Inter-hemispheric analysis of daytime low ionosphere behavior from 2007 to 2011. Journal of Atmospheric and Solar-Terrestrial Physics, 92: 51-8.

Fagundes, P.R.; Pillat, V.G.; Bolzan, M. J.A.; Sahai, Y.; Becker- Guedes, F.; Abalde, J.R.; Aranha S.L. \& Bittencourt , J.A. (2005). Observations of F-layer electron density profiles modulated by pw type oscillations in the equatorial ionospheric anomaly region. Journal of Geophysical Research, 110 (A12302): 1-8. 
Lastovicka, J. (2006). Forcing of the ionosphere by waves from below. Journal of Atmospheric and Solar-Terrestrial Physics, 68: 479-97.

MacDougall, J.W. (1997). Canadian Advanced Digital Ionosonde Users Manual. University of Western Ontario, Scientific Instrumentation. Ltd. 90p.

Newman, P.A.; Herman, R.; Bevilacqua, R.; Stolarski, R. \& Keating, T. (2008). Ozone and UV Observations. In: Ravishankara, A.R., Kurylo, M.J. \& Ennis, C.A. (Eds.). Trends in Emissions of Ozone-Depleting Substances, Ozone Layer Recovery, and Implications for Ultraviolet Radiation Exposure. Report by the US Climate Change Science Program and Subcommittee on Global Change Research. Department of Commerce, NOAA's Layer Recovery, and Implications for Ultraviolet Radiation Exposure National Climatic Data Center, Asheville, NC. p. 79-110.

Nicolet, M. \& Aikin, A.C. (1960). The Formation of the D-Region of the lonosphere. Journal of Geophysical Research, 65 (5): 1469-83.

Piggott, W.R. \& Rawer, K. (1972). U.R.S.I. Handbook of lonogram Interpretation and Reduction, World Data Center A for SolarTerrestrial Physics. NOAA, Boulder, CO. 90p.

Scherrer, D.; Cohen, M.; Hoeksema, T.; Inan, U.; Mitchell, R. \& Scherrer, P. (2008). Advances in Space Research, 42: $1777-85$.

Takahashi, H.; Batista, P.P.; Buriti, R.A.; Gobbi, D.; Tsuda, N.T. \& Fukao, S. (1999). Response of the airglow OH emission, temperature and mesopause wind to the atmospheric wave propagation over Singaraki, Japan. Earth Planets and Space, 51(7-8): 863-75.

Thomson, N.R. \& Clilverd, M.A. (2000). Solar cycle changes in daytime VLF subionospheric attenuation. Journal of Atmospheric and Solar-Terrestrial Physics, 62: 601-8.

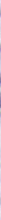

